\title{
Mesh repair of medium sized midline incisional hernias: Prolene mesh versus Vypro mesh
}

\author{
Mohammed A Nada, MD; Moustafa Hegazy, MS; Mohammed El-Shinawi, MD; \\ Ali M El-Anwar, MD; Hammed H Abo-Steit, MD; Ahmed S Morad, MD; \\ Ahmed M Lotfy, MD
}

\author{
Department of General Surgery, Ain Shams University, Cairo, Egypt.
}

\begin{abstract}
Incisional hernia is a complication in 10-20\% of patients after laparotomy. The standard flat mesh made from polypropylene has a tensile strength that is far greater than that required physiologically. Reducing the amount of polypropylene by increasing pore size produces a lighter weight mesh that may improve the functional properties and diminish local complications. The low-weight mesh was found to be feasible, with no additional short-term mesh-related complications in the experimental model and no negative side effect on biocompatibility. Also the introduction of the retromuscular, sublay technique using polypropylene meshes had significantly decreased the recurrence rates after open incisional hernia repair.

The aim of this study: To evaluate the sublay technique using light weight Vypro mesh in comparison to the same technique using heavy weight Prolene mesh for moderate size midline incisional hernias, as regard operative difficulties and postoperative complications.

Patient and method: Between Aug. 2008 and Aug. 2009, 30 patients with moderate size (5$10 \mathrm{~cm})$ midline incisional hernias were randomized to receive lightweight composite (Vypro) mesh, or standard polypropylene (Prolene) mesh. The clinical course of all patients was registered during the hospital stay as well as 3, 6, 9, and 12 months after surgery.

Results: No significant differences were determined concerning age and gender. In contrast, length of hospital stay was lower in the low-weight mesh group. Minor complications as seroma, mild wound infection and abdominal discomfort were significantly lower among patients in whom we used Vypro meshes in the repair than patients with prolene meshes. No hernia recurrences occurred in both studied groups.
\end{abstract}

\section{Introduction:}

Incisional hernias remain one of the most common surgical complications with a longterm incidence of $10-20 \% .{ }^{1}$ With the move to the tension-free repair following the introduction of the meshes, results improved, with a slight decrease in the rate of recurrence to approximately $10 \% .^{2}$

Within recent decades, the sublay prosthetic hernioplasty, which was introduced in the 1970 by the French surgeons Stoppa and Rives, became one of the widely accepted procedures for incisional hernia repair. ${ }^{3}$ This technique is basically characterized by mesh implantation in the "sublay"position below the rectus muscle and fixation of the mesh by transfascial sutures at the edges of the mesh. ${ }^{4}$
Polypropylene is the material widely used for open mesh repair. New developments have led to low-weight, large-pore (polypropylene and polygalactin mixture) prostheses "Vypro" meshes, which are adjusted to the physiological requirements of the abdominal wall and permit proper tissue integration. These meshes provide the possibility of forming a scar net instead of a stiff scar plate and therefore help to avoid the former known complications. ${ }^{5}$

Is the ideal mesh a heavyweight or a lightweight mesh?

Experimental and clinical data have lent scientific support to the theory that synthetic mesh materials, especially traditional "heavyweight', polypropylene mesh, are overengineered for their purpose. This excess 
prosthetic can lead to more complications, including decreased mesh flexibility, loss of abdominal wall compliance, inflammation, and scarring of surrounding tissues, potentially leading to pain, a sensation of feeling the mesh in the abdominal wall, and mesh contraction and wadding, which in turn may result in a recurrent hernia. ${ }^{6}$

\section{Patient \& method:}

Our study was a randomized double blind prospective study. It included 30 patients complaining of moderate size ventral incisional hernia (the size of hernia ranging from 5$11 \mathrm{~cm})$. All patients were consented to perform the study. Large and huge sized hernias were excluded as they need additional methods of repair. These patients were recruited from those attending the surgical outpatient clinic of Ain Shams University Hospital (El-Demerdash Hospital) and Sohag Teaching Hospital, during the period from Aug.2008 till Aug.2009.

The patients were classified into two groups:

Group A: Fifteen patients treated by sublay technique using the Heavy-weight Prolene mesh.

Group B: Fifteen patients treated by the same sublay technique but using the Lightweight Vypro mesh in their repair.

Follow up: Follow up of all patients was done at the $3 \mathrm{rd}$, 6th and 12 th month postoperatively stressing on post-operative complications as seroma formation, postoperative pain, wound infection, abdominal discomfort and recurrence.

\section{Preoperative preparation:}

\section{- History:}

Present History: Onset, course, duration, age, sex, occupation, weight, and special habits (smoking).

Past History: History of previous operations regarding the type of incision and the etiology (peritonitis, para umbilical hernia and exploratory incisions).

History of chronic illness: Hypertension, diabetes, congenital heart disease, corticosteroid therapy, BPH and COPD.

Family History: Incisional hernia, congenital hernia and acquired hernia.

- General examination: Pulse, B.P, chest and heart.
- Abdominal (Local) examination: Scar for midline incision, site, size of hernia, irreducibility and other complications.

- Investigations: CBC, blood sugar, blood urea, serum creatinine, liver function tests, prothrombin time, prothrombin concentration, urine analysis, ECG and abdominal ultrasonography.

\section{Operative details:}

Repair is done using retromuscular sublay mesh repair (mesh implanted behind the rectus abdominis muscle in front of the closed posterior rectus sheath and peritoneum). The steps of the operation in our study follow the published technique of sublay mesh repair, 5,8 stressing on the following technical points:

- The posterior rectus sheath and the peritoneum were closed by continuous nonabsorbable sutures to prevent direct contact between mesh and intestine.

- The mesh was sized to give an overlap of at least $5 \mathrm{~cm}$ in all directions from the aponeurotic edges.

- The mesh is trimmed to fit the specific dimensions of the defect to be treated.

- Respecting the physiological elasticity of the abdominal muscle fibers, the mesh should feature its main elasticity in a vertical direction. This ensures adaptation to the physiological stretch ability of the abdominal wall and reduces craniocaudal shrinkage by mesh deformation.

- Fixation of the mesh was performed employing nonabsorbable interrupted sutures.

- During fascia closure wrinkling of the mesh should be avoided. Working as thrustbearing and preventing early strain to the mesh, closure of the anterior fascia is imperative and should be done with undue tension.

- Drainage with suction drains (retromuscular space) was mandatory before wound closure.

\section{Materials:}

Prolene mesh and light weight (Vypro) meshes: manufactured by Ethicon $\mathrm{GmbH}$, Norderstedt, Germany. 


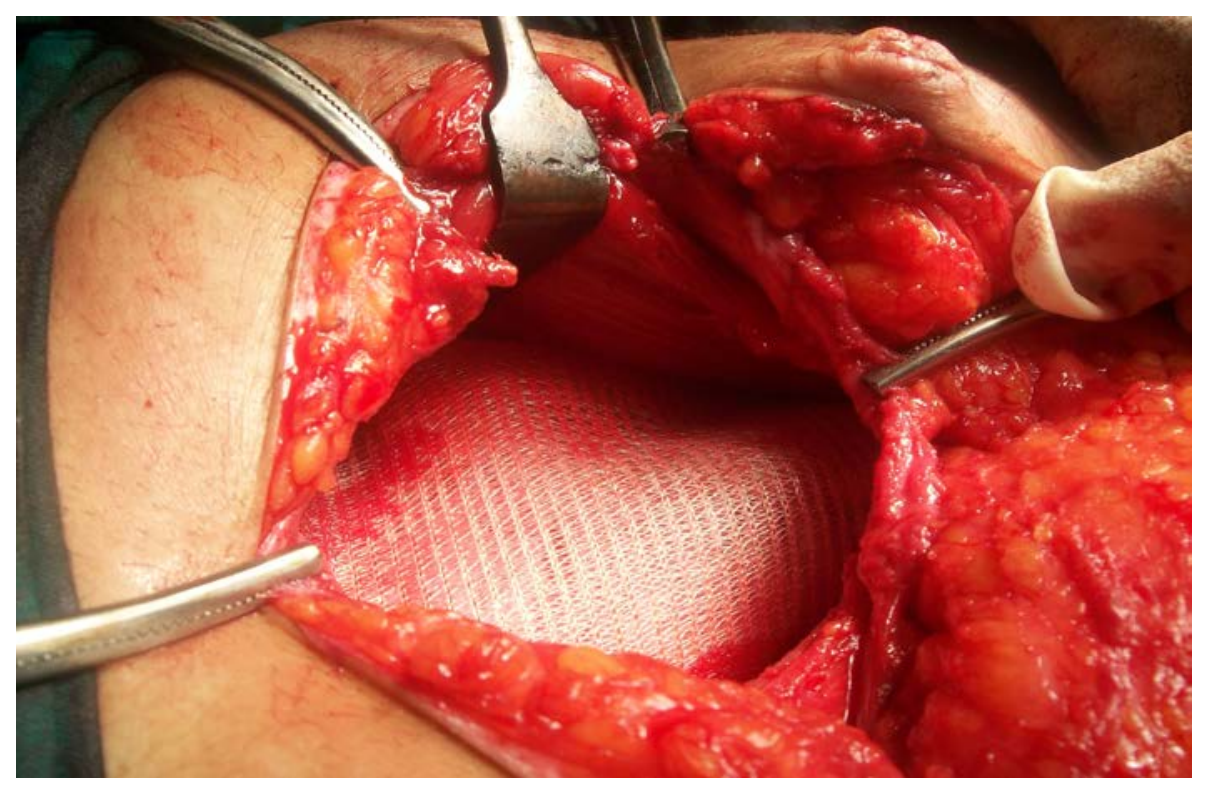

Figure (1): Mesh placement (Prolene mesh).

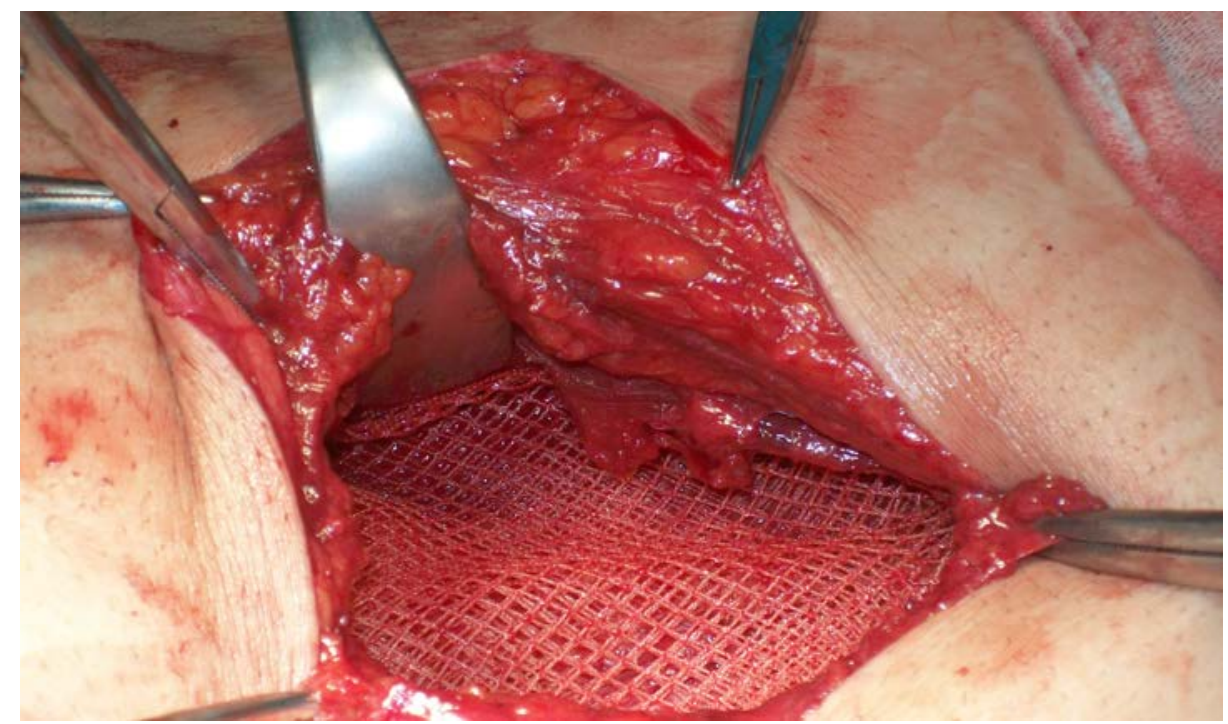

Figure (2): Mesh placement (Vypro mesh).

Postoperative care: is mainly directed to the control of wound problems and mobility restriction is required for no longer than the first 24 hours.

\section{Results:}

The sublay technique of mesh repair in both groups of patients was evaluated through certain selected parameters which include; - Sex

- Age
- Type of hernia; primary(upper and lower),or recurrent

- Operative time

- Duration and amount of suction

- Hospital stay

- Postoperative complications stressing on;
(1) Seroma
(2) Wound Infection
(3) Abdominal discomfort
(4) Recurrence 
Table (1): Distribution of cases in relation to gender.

\begin{tabular}{|l|c|c|c|c|c|c|}
\hline & \multicolumn{2}{|c|}{$\begin{array}{c}\text { Group A } \\
(\mathbf{n = 1 5})\end{array}$} & \multicolumn{2}{c|}{$\begin{array}{c}\text { Group B } \\
(\mathbf{n = 1 5})\end{array}$} & \multicolumn{2}{|c|}{ P value } \\
\cline { 2 - 7 } & No. & $\%$ & No. & $\%$ & Value & Significance \\
\hline Male & 8 & $53.3 \%$ & 9 & $60 \%$ & $>0.05$ & Not Significant \\
\hline Female & 7 & $46.7 \%$ & 6 & $40 \%$ & $>0.05$ & Not Significant \\
\hline
\end{tabular}

Table (2): Age ditribution between both groups.

\begin{tabular}{|l|c|c|c|c|}
\hline & \multicolumn{2}{|c|}{ Age (years) } & \multicolumn{2}{c|}{ P value } \\
\cline { 2 - 3 } & Mean & SD & Value & Significance \\
\hline Group A & 46.73 & 6.3 & \multirow{2}{*}{$>0.05$} & Not Significant \\
\hline Group B & 45.73 & 8.38 & & \\
\hline
\end{tabular}

Table (3): Classification of incisional hernia in both groups.

\begin{tabular}{|l|c|c|c|c|c|c|}
\hline & \multicolumn{2}{|c|}{$\begin{array}{c}\text { Group A } \\
(\mathbf{n}=15)\end{array}$} & \multicolumn{2}{c|}{$\begin{array}{c}\text { Group B } \\
(\mathbf{n = 1 5})\end{array}$} & \multicolumn{2}{c|}{$\begin{array}{c}\text { Total } \\
(\mathbf{n}=30)\end{array}$} \\
\cline { 2 - 7 } & No. & $\%$ & No. & $\%$ & No. & $\%$ \\
\hline 1ry inc. hernia & 13 & 86.7 & 15 & 100 & 28 & 93.3 \\
\hline Rec inc. hernia & 1 & 6.7 & 0 & 0 & 1 & 3.3 \\
\hline Rec after mesh & 1 & 6.7 & 0 & 0 & 1 & 3.3 \\
\hline
\end{tabular}

Table (4): Operative time.

\begin{tabular}{|c|c|c|c|c|}
\hline \multirow{2}{*}{} & \multicolumn{2}{|c|}{ Time (min.) } & \multicolumn{2}{c|}{ P value } \\
\cline { 2 - 3 } & Mean & SD & Value & Significance \\
\hline Group A & $80-120(100.67)$ & 12.2 & $>0.05$ & \multirow{2}{*}{ Not Significant } \\
\hline Group B & $85-125(103.67)$ & 13.4 & & \\
\hline
\end{tabular}

Table (5): Duration of suction.

\begin{tabular}{|l|c|c|c|c|}
\hline \multirow{2}{*}{} & \multicolumn{2}{|c|}{ Duration (day) } & \multicolumn{2}{c|}{ P value } \\
\cline { 2 - 3 } & Mean & SD & Value & Significance \\
\hline Group A & $4-7$ days (5.8) & 0.94 & $<0.01$ & Significant \\
\hline Group B & $3-5$ days (4.4) & 0.73 & & \\
\hline
\end{tabular}


Table (6): Amount of suction.

\begin{tabular}{|l|c|c|c|c|}
\hline & \multicolumn{2}{|c|}{ Amount (mL) } & \multicolumn{2}{c|}{ P value } \\
\cline { 2 - 4 } & Mean & SD & Value & Significance \\
\hline Group A & $70-150(102.0) \mathrm{ml}$ per day & 23.05 & \multirow{2}{*}{$<0.05$} & Significant \\
\hline Group B & $50-110(85.3) \mathrm{ml}$ per day & 16.85 & & \\
\hline
\end{tabular}

Table (7): Postoperative hospital stay.

\begin{tabular}{|l|c|c|c|c|}
\hline & \multicolumn{2}{|c|}{ Hospital stay (day) } & \multicolumn{2}{c|}{ P value } \\
\cline { 2 - 3 } & Mean & SD & Value & Significance \\
\hline Group A & $10-15(12.33)$ & 2.58 & \multirow{2}{*}{$>0.05$} & Not Significant \\
\hline Group B & $9-14(11.87)$ & 1.73 & & \\
\hline
\end{tabular}

Table (8): Chronic post-operative pain.

\begin{tabular}{|l|c|c|c|c|c|c|c|c|}
\hline & \multicolumn{2}{|c|}{$\begin{array}{c}\text { Group A } \\
(\mathbf{n = 1 5})\end{array}$} & \multicolumn{2}{|c|}{$\begin{array}{c}\text { Group B } \\
(\mathbf{n = 1 5})\end{array}$} & \multicolumn{2}{c|}{$\begin{array}{c}\text { Total } \\
(\mathbf{n = 3 0})\end{array}$} & \multicolumn{2}{|c|}{ P value } \\
\cline { 2 - 9 } & No. & $\%$ & No. & $\%$ & No. & $\%$ & Value & Significance \\
\hline $\begin{array}{l}\text { First month } \\
\text { visit }\end{array}$ & 2 & $13.3 \%$ & 1 & $6.7 \%$ & 3 & $10 \%$ & $>0.05$ & $\begin{array}{c}\text { Not } \\
\text { Significant }\end{array}$ \\
\hline $\begin{array}{l}\text { 12th month } \\
\text { visit }\end{array}$ & 1 & $6.7 \%$ & 0 & $0 \%$ & 1 & $3.3 \%$ & $>0.05$ & Significant \\
\hline
\end{tabular}

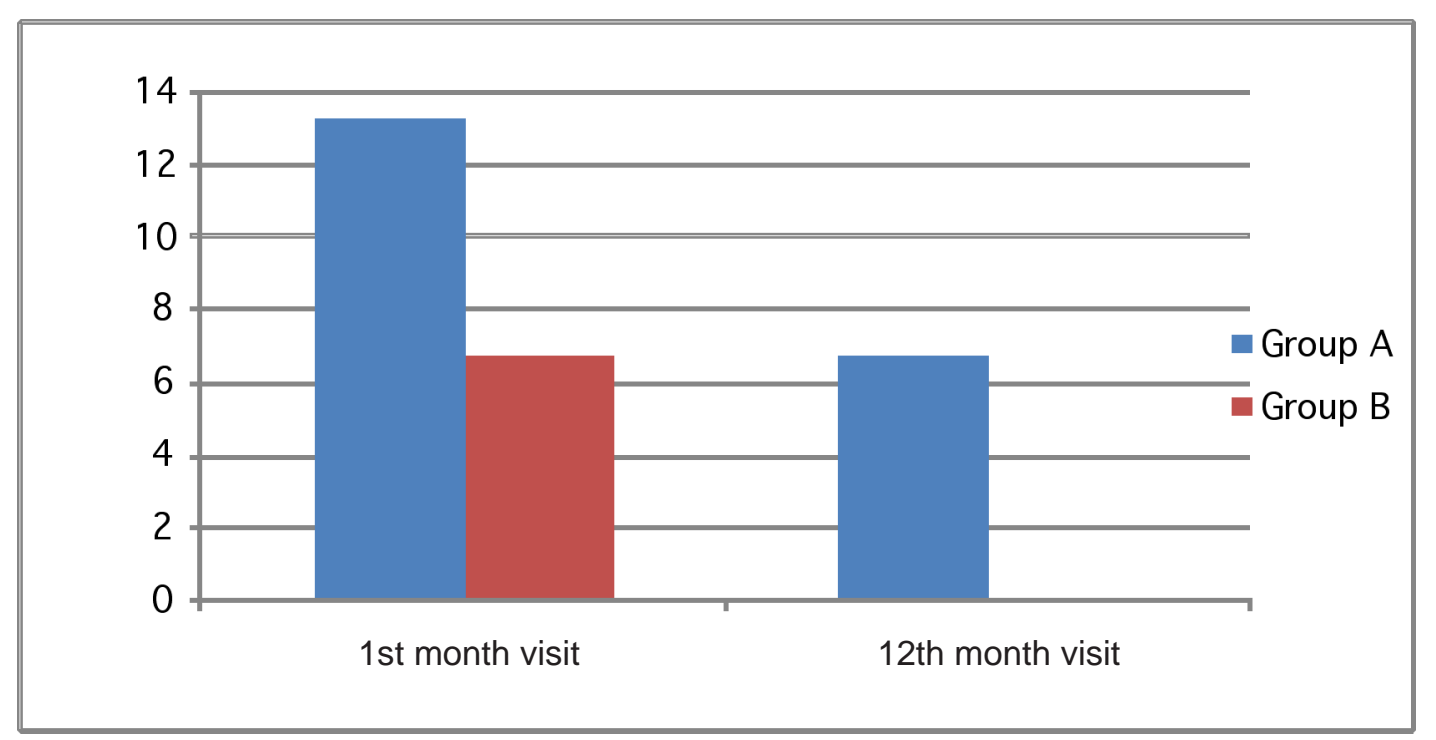

Chart (1): Post-operative pain. 
Table (9): Post-operative complications.

\begin{tabular}{|l|c|c|c|c|c|c|}
\hline \multirow{2}{*}{} & \multicolumn{2}{|c|}{$\begin{array}{c}\text { Group A } \\
(\mathbf{n = 1 5})\end{array}$} & \multicolumn{2}{c|}{$\begin{array}{c}\text { Group B } \\
(\mathbf{n = 1 5})\end{array}$} & \multicolumn{2}{c|}{ P Value } \\
\cline { 2 - 7 } & No. & $\%$ & No. & $\%$ & Value & Significance \\
\hline Seroma & 4 & $26.7 \%$ & 2 & $13.3 \%$ & $<0.05$ & Significant \\
\hline Wound Infection & 3 & 20.0 & 1 & $6.7 \%$ & $<0.01$ & Significant \\
\hline
\end{tabular}

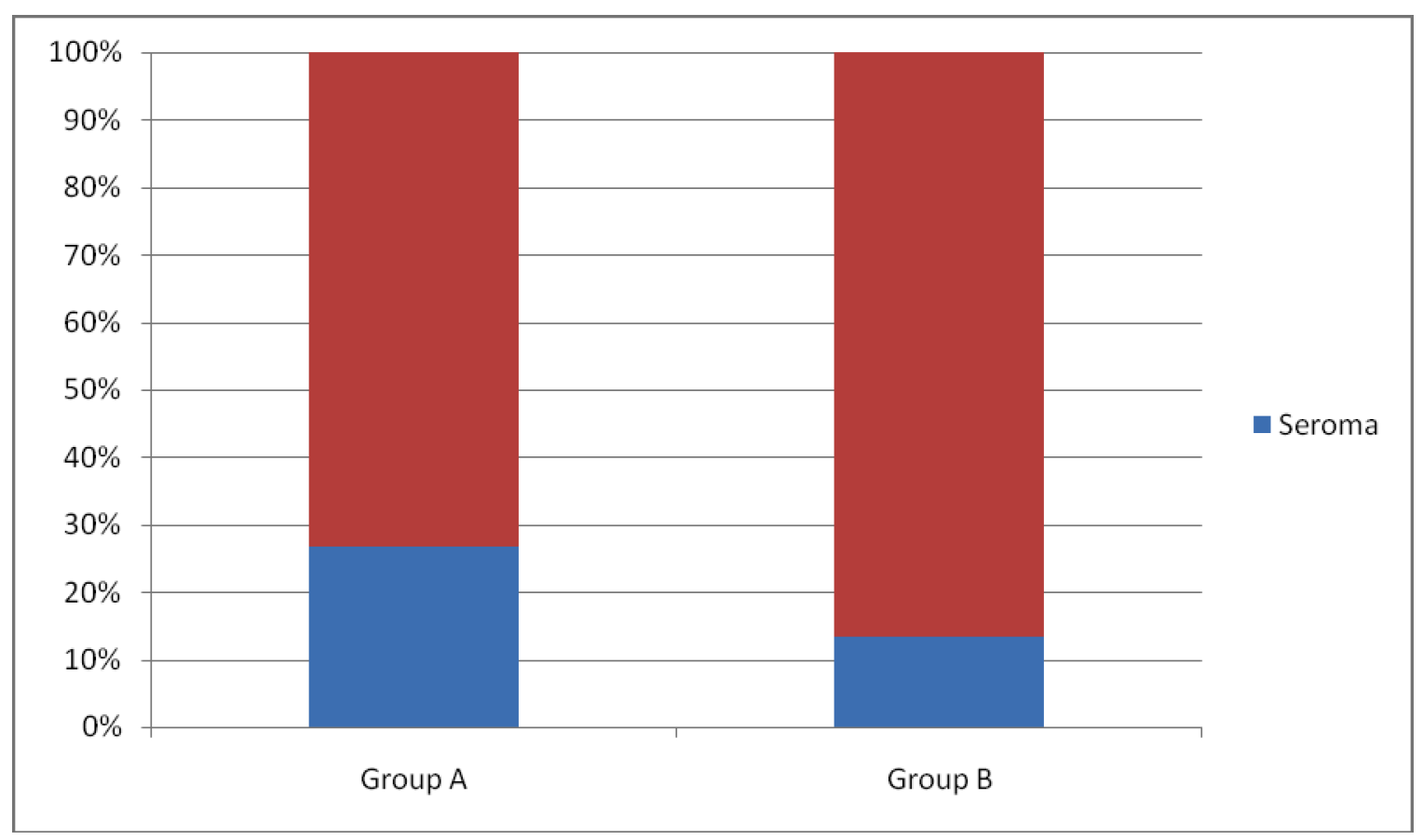

Chart (2): Seroma.



Chart (3): Wound infection. 
None of our patients had a recurrence through the first year postoperatively but unfortunately, two patients were lost during follow up both after the ninth month visit, one from each group, so these 2 patients were classified as recurrence $\mathrm{x}$ subgroup.

\section{Statistical study:}

The data was processed by using SPSS version 9.0. Descriptive statistical study was used to determine the frequency and percentage. The level of significance between the groups was determined using the independent $t$ - test, as well as chi square test.

\section{Discussion:}

Our study was designed to compare two different types of synthetic meshes; heavyweight mesh (Prolene mesh) and light-weight mesh (Vypro mesh) in repair of moderate size ventral incisional hernia using the sublay retromuscular repair with follow up 12 months postoperatively for the post operative complications specially seroma formation, wound infection, chronic post operative pain, and recurrences.

Analysis of the obtained data of both groups revealed the following:

No significant differences were determined concerning the operative time as the operative technique is the same in both groups Table(4). This agrees with the study done by Conze and associates, 2005. ${ }^{7}$

The amount and duration of suction was higher in group (A) Prolene mesh, than group (B) Vypro mesh Table(5,6), which is mostly claimed to the less tissue reaction that occur after fixation of light weight mesh.

There were no great significant difference considering hospital stay in both groups Table(7), but in group (A) the relative long hospital stay was a consequence of the later removal of the drain and larger amount of drained fluid than group (B).

After one year of follow up there was only one patient with persistent neuralgia and the mesh used in that patient was Prolene mesh Table(8), Chart(1). However Conz and associates, $2005^{7}$ observed a higher incidence of chronic post operative pain (after one year from the repair) with Prolene mesh (17.9\%) than between patients who had light weight meshes in their repair (3.6\%). Schmidbauer and co-workers, $2005^{8}$ reported that, "in the long-term run (mean follow-up $92+/-20$ months), patients of the heavy-weight (Prolene) mesh group complained significantly more frequent from chronic pain and stiff abdomen than those of the low-weight (Vypro) mesh group (46 +/- 14 months). This could be attributed to the rigid nature and lesser flexibility of Prolene mesh than the flexible, soft handled Vypro mesh. This explanation agrees with Schumpelick and co-workers, $2007^{9}$ explanation for the higher incidence of chronic postoperative pain following hernia repair with Prolene mesh, than with any light weight mesh.

There was not any sizeable seroma noticed among our patients that required surgical intervention Table(9), Chart(2). All patients with seroma were completely free within the first 6 weeks. We agree with the statement of Schumpelick and co-workers, $2006,{ }^{5}$ that "postoperative seroma ranges from 14.5-45\% of implantations so the application of drainage for 3-7 days is recommended". The low incidence of seroma among our patients can be claimed to the lesser number of patients we had also it may be claimed to the relatively small size hernias that we included in our study.

The incidence of seroma formation following removal of the suction drains was higher in group (A) Prolene meshes than in group (B) Vypro meshes, this could be explained by the fact that the Prolene mesh induces a strong and relatively long lasting foreign body reaction, as the prolene meshes are often constructed with monofilament with a small pore size and a heavyweight character but Vypro mesh with reduction of $70 \%$ of the polypropylene filaments, and large pore size induces less inflammatory reaction..$^{5}$ Our results agree with the study of Conze and associates, $2005,{ }^{7}$ which claimed that; although fewer seromas were observed at 21 days after the standard (Prolene) mesh repair, there were more seromas (4-24 months postoperatively) between patients with Prolene mesh than with the composite (Vypro) mesh.

None of our patients had deep or long standing wound infection Table(9), Chart(3). 
The infections among our patients were mostly subcutaneous and no mesh removal was necessary. This result agrees with the statement of Schumpelick and co-workers, $2006^{5}$ that "infections may be expected in about $10 \%$ of the patients and it is usually restricted to the subcutaneous space and they should be treated conservatively as common wound infections. Even if the infection encroaches into the mesh itself, a conservative attempt is justifiable, provided the mesh is porous". However, incidence of infection was greater in group (A) than in group (B) and these results agree with those obtained in a study done by Schmidbauer and co-workers, 2005.8

Though there is controversy between our study and Conze et al., $2005^{7}$ as they observed no difference between both groups as regard wound infection but surprisingly they noticed a near incidence of wound infection as regard the whole patients, they mentioned an incidence of 4-16\% and we observed an incidence of 13$20 \%$.

Conze and co-workers, $2005^{7}$ reported that the recurrence rate was $17 \%$ for the lightweight mesh and $7 \%$ for the standard mesh and they claimed that to, firstly the fixation of the mesh with absorbable suture materials, secondly to the inadequate overlap of the mesh to the cranial edge of the hernia so we tried in our study to avoid these possible causes of recurrence to evaluate accurately both materials. While, Schmidbauer et al., $2005^{8}$ study showed that; large pore-sized, low-weight meshes composed of multifilaments are clearly to be favored over large pore-sized, monofilament heavy-weight polypropylene meshes because of better abdominal wall compliance and less chronic pain. However, both types of meshes are convincing due to high tensile strength and low recurrence rates in the long-term run.

In our study there was no recurrence in both groups after follow up of one year postoperatively but there was one patient lost during follow up in each group as they didn't attend the 12th month visit. Absence of recurrence in our study may be due to short-term follow up compared to the long-term follow up in the other international studies and also we had only 30 patients that were included in our study.

\section{Conclusion:}

The use of the lightweight composite (Vypro) mesh for incisional hernia repair had similar outcomes to heavyweight polypropylene mesh, but lightweight mesh proved better abdominal wall compliance, less chronic pain, lower incidences of postoperative seroma and infections. As compared to the heavyweight meshes, the lighter-weight meshes show a decrease in inflammatory response, decreased stiffness, less shrinkage, and fewer complaints from patients. Thus now we have evidence that if the surgeon chooses a polypropylene, it should be a lightweight mesh if possible.

\section{References:}

1- Van't Riet M, Steyerberg EW, Nellensteyn $\mathrm{J}$, Bonjer, et al: Meta-analysis of techniques for closure of midline abdominal incisions. Br J Surg 2002; 89: 1350-1356.

2- Kingsnorth A, LeBlanc K: Hernias: Inguinal and incisional. Lancet 2003; 362: 15611571.

3- Millikan KW: Incisional hernia repair. Surg Clin North Am 2003; 83: 1223-1234.

4- Petersen S, Henke G, Zimmermann L, et al: Ventral rectus fascia closure on top of mesh hernia repair in sublay technique. Plas Rec Surg 2004; 114(7): 1754-1760.

5- Schumpelick V, Klinge U, Rosch R, et al: Light weight meshes in incisional hernia repair. Min Acess Surg 2006; 2(3): 117123.

6- Coda A, Bendavid R, Botto-Micca F, et al: Structural alterations of prosthetic meshes in humans. Hernia 2003; 7(1): 29-34.

7- Conze J, Kingsnorth AN, Flament JB, et al: Randomized clinical trial comparing lightweight composite mesh with polyester or polypropylene mesh for incisional hernia repair. Br J Surg 2005; 92(12): 1488-1493.

8- Schmidbauer S, Ladurner R, Hallfeldt KK, et al: Heavy-weight versus low-weight polypropylenemeshes for open sublay mesh repair of incisional hernia. Eur J Med Res 2005; 10(6): 247-253.

9- Schumpelick V, Klinge U, Rosch R, et al: How to treat the recurrent incisional hernia: Open repair in the midline inc. recurrent hernia. Prevention \& Treatment 2007; 191196. 